\title{
Effect of Initial Microstructure on Soft Annealing of a Low-Car- bon Bainitic Steel
}

\author{
Lei Zhu ${ }^{1}$, Ying Yang ${ }^{1}$, Yuyang Li ${ }^{1}$, Huanhuan Xuan ${ }^{1}$, Hongtao Chen ${ }^{2}$, Yanxiang Zhang ${ }^{1}$, Mufu Yan ${ }^{1, *}$ \\ 1 School of Material Science and Engineering, Harbin Institute of Technology, Harbin 150001, Heilongjiang, \\ China; 19S009069@stu.hit.edu.cn (L.Z.); 20B909029@stu.hit.edu.cn (Y.Y.); 20B909030@stu.hit.edu.cn (Y.L.); \\ prsm804@163.com (H.X.); hitzhang@hit.edu.cn (Y.Z.); \\ 2 School of Material Science and Engineering, Harbin University of Science and Technology, Harbin 150040, \\ Heilongjiang, China; htchen83@163.com (H.C.); \\ * Correspondence: yanmufu@hit.edu.cn (M.Y.);
}

Citation: Zhu, L.; Yang, Y.; Li, Y.;

Xuan, H.; Chen, H.; Zhang, Y.; Yan,

M. Effect of Initial Microstructure on Soft Annealing of a Low-Carbon

Bainitic Steel. 2021, 3, x.

https://doi.org/10.3390/xxxxx

Published: 22 February 2021

Publisher's Note: MDPI stays neutral with regard to jurisdictional claims in published maps and institutional affiliations.

Copyright: $₫ 2021$ by the authors. Submitted for possible open access publication under the terms and conditions of the Creative Commons Attribution (CC BY) license (http://creativecommons.org/licenses/by/4.0/).

\begin{abstract}
A low-carbon bainitic tool steel exhibiting high hardness after hot rolling typically has poor machinability. To soften this type of steel and to accelerate the soft annealing process, an austenitizing step was designed based on thermodynamic calculations of phase stability and introduced prior to the annealing step. Different initial microstructures were prepared by three austenitizing temperatures $\left(680{ }^{\circ} \mathrm{C}, 850{ }^{\circ} \mathrm{C}, 1000{ }^{\circ} \mathrm{C}\right.$ ) and three cooling methods (water quenching, oil quenching, and air cooling). The effect of initial microstructure on microstructures and hardness was studied. Softening equations, function of annealing temperature and time, were established for different initial microstructures, and the relationships between annealing temperature, annealing time, activation energy and hardness were explored. The predicted hardness was consistent with the measured values. Martensitic structure has a low activation energy for diffusion and a higher softening rate compared to that of the bainitic structure. In addition, the higher carbide content in the bainitic structure, the smaller the activation energy tended to be.
\end{abstract}

Keywords: soft annealing; initial microstructure; hardness; softening equation

\section{Introduction}

The service conditions of drilling tools are very harsh, i.e., heavy abrasion of the rock, the corrosion of soil and water, and the frequenct impact of the piston. Simultaneously, it also bears multiplied loads such as tension, torsion, shear and bending stress [1, 2]. These steels are typically bainitic which can easily form during cooling [3-8]. Hence, annealing treatment must be carried out to reduce the hardness for the requirement of machinability.

Usually, an annealing routine is to hold at a temperature near Ac1 of the steel for a long time to obtain an equilibrium or quasi-equilibrium microstructure. At present, spheroidizing annealing is a commonly used annealing softening process to obtain divorced pearlite $[9,10]$. It can significantly reduce the strength and hardness of steel and improve toughness, which is generally used for hypereutectoid steel or high carbon steel as a preliminary heat treatment. According to many studies, the spheroidization rate is very slow [11]. Many attempts have been carried out to accelerate the spheroidization process, such as adding Al element [12], using cyclic heat treatment [13], applying ultra-fast cooling to avoid carbide network [14], adjusting the deformation processing parameters [15], conditioning the initial microstructure before annealing [16], and etc. However, lots of studies are focused on hypereutectoid steel or high carbon steel. And there are few reports on annealing softening of low-carbon steel whose initial microstructure is bainite or martensite. 
In this study, a series of austenitizing routines were designed to prepare different microstructures for low-carbon bainitic steel before soft annealing. The effects of initial microstructures on microstructures and hardness were explored and described through the softening equations.

\section{Materials and Methods}

\subsection{Materials}

The material used in this study was a commercial low-carbon bainitic steel named CTHQ25, which was provided by Pangang Jiangyou Changcheng Special Steel Co., Ltd, China. A hot-rolled bar was machined into $12 \mathrm{~mm} \times 12 \mathrm{~mm} \times 6 \mathrm{~mm}$ samples by wire cutting. The chemical composition of the steel were listed in Table 1. The Brinell hardness of the steel in the as-recieved condition was $371 \mathrm{HB}$.

Table 1. Chemical composition of CTHQ25 steel (wt.\%)

\begin{tabular}{cccccccccc}
\hline $\mathrm{C}$ & $\mathrm{Si}$ & $\mathrm{Mn}$ & $\mathrm{Cr}$ & $\mathrm{Ni}$ & $\mathrm{Mo}$ & $\mathrm{V}$ & $\mathrm{Cu}$ & $\mathrm{P}$ & $\mathrm{S}$ \\
\hline $0.23 \sim$ & $1.30 \sim$ & $1.30 \sim$ & $0.35 \sim$ & $1.75 \sim$ & $0.50 \sim$ & $0.15 \sim$ & $\leq$ & $\leq$ & $\leq$ \\
0.26 & 1.50 & 1.50 & 0.55 & 2.00 & 0.65 & 0.25 & 0.20 & 0.010 & 0.008 \\
\hline
\end{tabular}

In order to investigate the effect of initial structure on soft annealing, austenitizing was designed with different austenitizing temperatures and cooling methods. Based on the chemical composition of the steel, $\mathrm{A}_{1}, \mathrm{~A}_{3}$ and VC-solvus temperature were calculated by Thermo-Calc software with TCFE9 database. They were about $650{ }^{\circ} \mathrm{C}, 790^{\circ} \mathrm{C}$ and 950 ${ }^{\circ} \mathrm{C}$, respectively. Therefore, the austenitizing temperature were selected as $680{ }^{\circ} \mathrm{C}, 850{ }^{\circ} \mathrm{C}$ and $1000{ }^{\circ} \mathrm{C}$. After holding at the austenitizing temperature for $1 \mathrm{~h}$, the samples were cooled by three different cooling methods (water quenching, oil quenching and air cooling) to obtain 9 different initial microstructures. The subsequent annealing process was carried out for $48 \mathrm{~h}$ at different annealing temperatures ranging from 500 to $700{ }^{\circ} \mathrm{C}$. The as-received sample was also annealed for comparison.

Samples after heat treatment were ground with 240\#-1500\# SiC abrasive paper and polished with $0.5 \mu \mathrm{m}$ diamond paste. The morphology of different microstructures was characterized by FEI Sirion 2000 scanning electron microscope after etched by $5 \%$ Nital solution. Brinell hardness was measured in 310HBS-3000 hardness tester with a $5 \mathrm{~mm}$ spherical indenter and applying $750 \mathrm{kgf}$ for $15 \mathrm{~s}$. The hardness of each sample was taken as the mean of three measurements.

\section{Results and Discussion}

\subsection{Initial microstructures}
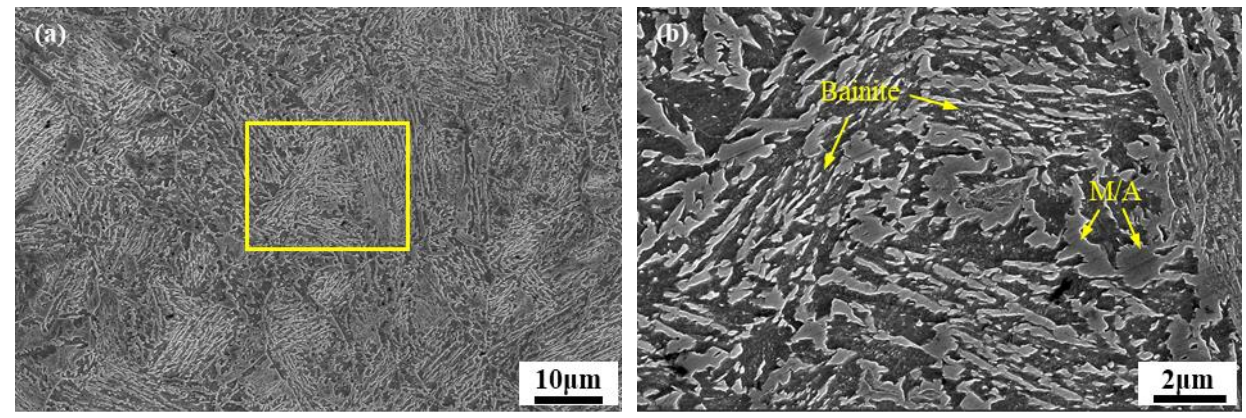

Figure 1. (a) SEM micrographs of hot-rolled sample; (b) Enlarged image of the yellow square in (a).

Figure 1 showed the microstructure of the hot-rolled sample. The bainite mainly consists of martensite/retained austenite (M/A) islands and lath-shaped bainitic ferrite as shown in Figure 1(a), corresponding to the Brinell hardness of $371 \mathrm{HB}$. There were very 
few carbides in the bainite due to the high Si content, which inhibits the precipitation of cementite.
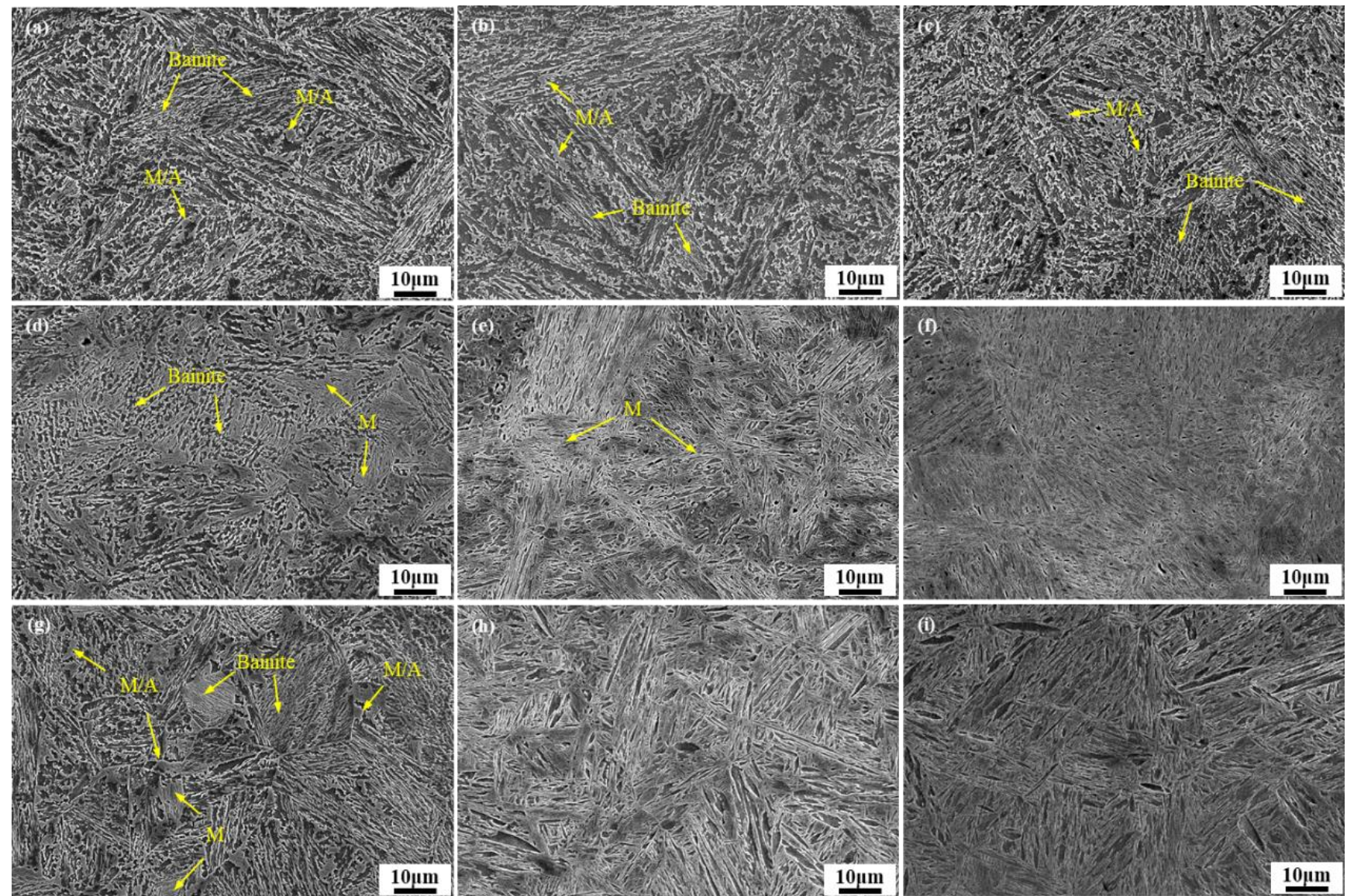

Figure 2. SEM micrographs of different initial microstructures obtained by different austenitizing process. (a) 680 ${ }^{\circ} \mathrm{C} / 1 \mathrm{~h} / \mathrm{AC}$;(b) $680^{\circ} \mathrm{C} / 1 \mathrm{~h} / \mathrm{OQ}$;(c) $680^{\circ} \mathrm{C} / 1 \mathrm{~h} / \mathrm{WQ}$;(d) $850^{\circ} \mathrm{C} / 1 \mathrm{~h} / \mathrm{AC}$; (e) $850^{\circ} \mathrm{C} / 1 \mathrm{~h} / \mathrm{OQ}$; (f) $850^{\circ} \mathrm{C} / 1 \mathrm{~h} / \mathrm{WQ} ;(\mathrm{g}) 1000^{\circ} \mathrm{C} / 1 \mathrm{~h} / \mathrm{AC}$; (h) $1000^{\circ} \mathrm{C} / 1 \mathrm{~h} / \mathrm{OQ}$; (i) $1000^{\circ} \mathrm{C} / 1 \mathrm{~h} / \mathrm{WQ}$.

Different initial microstructures after austenitizing were shown in Figure 2. It can be observed that holding at $680^{\circ} \mathrm{C}$ can only realize partial austenitization of the hot-rolled samples. The structures mainly consist of bainite ferrite, M/A islands and a few carbides with different cooling methods, which were similar to that of the hot-rolled.

However, it should be noted that some bainitic ferrite laths with high aspect ratio break down during the incomplete austenitizing. When the austenitizing temperature is chosen at 850 or $1000{ }^{\circ} \mathrm{C}$, complete austenitization can be achieved. Therefore, the structure is martensite at higher cooling rates and bainite or a mixture of bainite and martensite at lower cooling rates. 


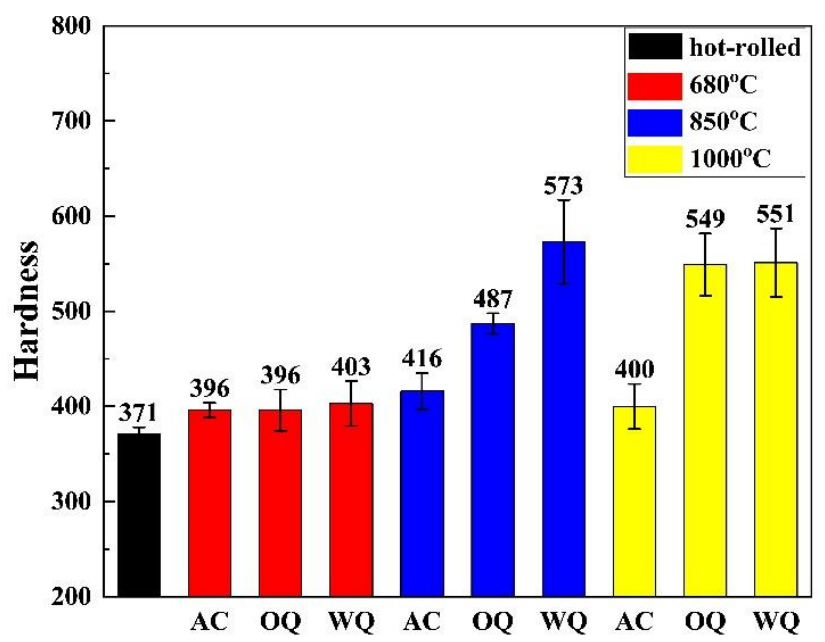

Figure 4. Hardness of different initial microstructures obtained by different austenitizing methods with as-received hot-rolled sample as comparison.

The Brinell hardness testing was performed on different initial microstructures, and the results were shown in Figure 4. For comparison, the Brinell hardness of the as-received hot-rolled steel was also listed. It can be seen that the Brinell hardness of the $1000{ }^{\circ} \mathrm{C} / \mathrm{WQ}$, $1000^{\circ} \mathrm{C} / \mathrm{OQ} 850^{\circ} \mathrm{C} / \mathrm{AC}$ samples were higher than $500 \mathrm{HB}$, typical hardness of martensite. The hardness of $850^{\circ} \mathrm{C} / \mathrm{OQ}$ was $487 \mathrm{HB}$, which lies between the hardness of bainite and martensite. The hardness of the other specimens were close to $400 \mathrm{HB}$, which were slightly higher than the hardness of the hot-rolled sample, corresponding to the bainite structure.

\subsection{Soft annealing}

When annealed at $680{ }^{\circ} \mathrm{C}$ and $700{ }^{\circ} \mathrm{C}$ for $48 \mathrm{~h}$, the softening effect of all initial structures was the most significant, and the hardness of some initial microstructures were reduced to less than $260 \mathrm{HB}$, criterion for good machinability. The ideal annealed structure with lower hardness is a mixed structure of quasi-equiaxed ferrite and granular carbides, as shown in Figure 5 (a). Comparing Figure 5 (a) and (b), it can be found that when the annealing temperature is $680^{\circ} \mathrm{C}$, the initial microstructure has little effect on hardness and structure after annealing. The microstructures of $680^{\circ} \mathrm{C} / 1 \mathrm{~h} / \mathrm{AC}$ and $850^{\circ} \mathrm{C} / 1 \mathrm{~h} / \mathrm{AC}$ after annealing were equiaxed ferrite and granular carbides, and the corresponding hardness were $249 \mathrm{HB}$ and $247 \mathrm{HB}$, respectively. When the annealing temperature is $700{ }^{\circ} \mathrm{C}$, higher percentage of $\mathrm{M} / \mathrm{A}$ islands in the initial microstructure, such as $850^{\circ} \mathrm{C} / 1 \mathrm{~h} / \mathrm{AC}$, results in higher hardness after annealing. And partially decomposed M/A islands still remain, as shown in Figure 5(d). 


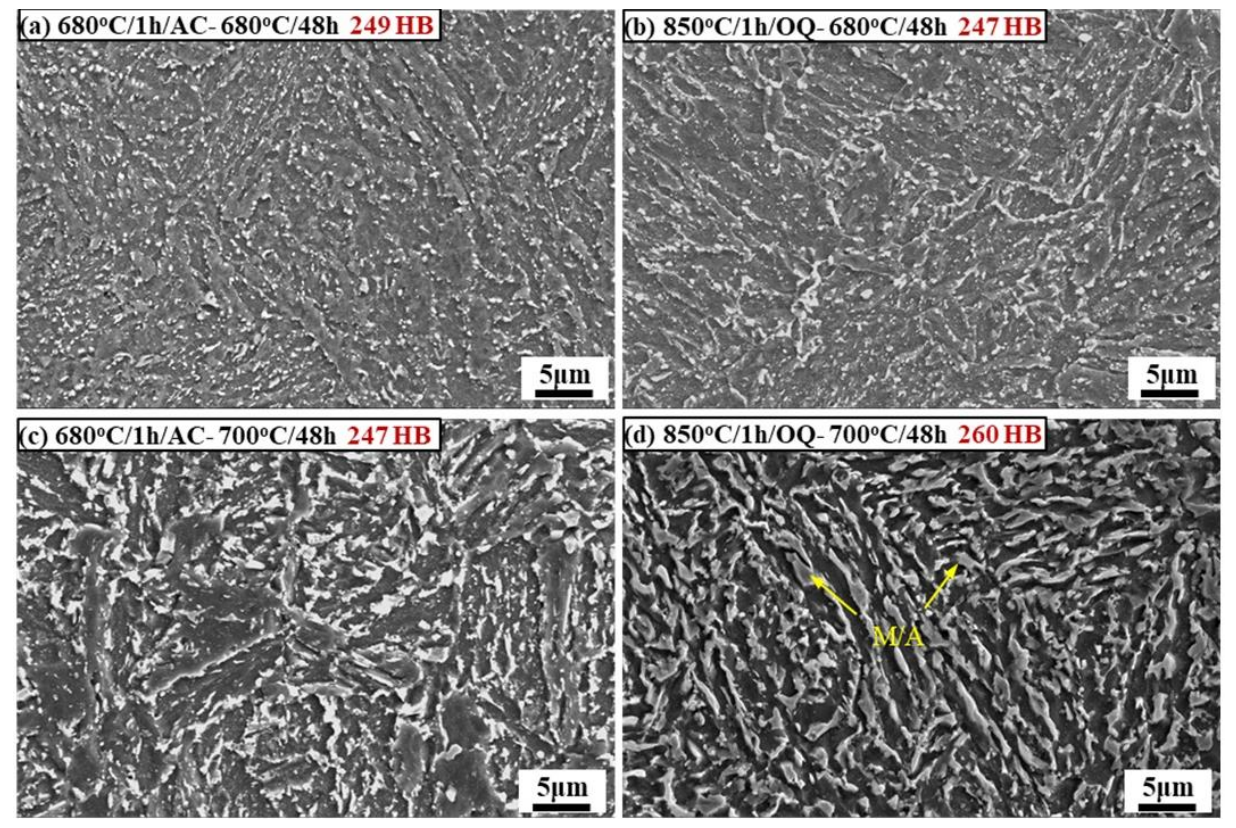

Figure 5. Microstructure of sample austenitized and then annealing: (a) $680^{\circ} \mathrm{C} / 1 \mathrm{~h} / \mathrm{AC}-680^{\circ} \mathrm{C} / 48 \mathrm{~h}$, (b) $850^{\circ} \mathrm{C} / 1 \mathrm{~h} / \mathrm{AC}-680^{\circ} \mathrm{C} / 48 \mathrm{~h}$, (c) $680^{\circ} \mathrm{C} / 1 \mathrm{~h} / \mathrm{AC}-700^{\circ} \mathrm{C} / 48 \mathrm{~h}$, (d) $850^{\circ} \mathrm{C} / 1 \mathrm{~h} / \mathrm{AC}-680^{\circ} \mathrm{C} / 48 \mathrm{~h}$.

\subsection{Soft annealing equation}

The softening equations as a function of $\lambda$-value were established for different initial microstructures based on the hardness data from experiments. The microstructure evolution during annealing was the result of the diffusion of atoms at the thermally activated state. Hence, the reaction rate could be described by Arrhenius equation. The amount of reaction $C$ for a certain time can be described by the following expression,

$$
C=v t=A t \exp \left(-\frac{Q}{R T}\right)
$$

where $Q$ is the activation energy $(\mathrm{J} / \mathrm{mol}), R$ is gas constant, $T$ is annealing temperature $(\mathrm{K})$, and $t$ is the annealing time $(\mathrm{h})$. The value of activation energy reflects the barrier of phase transformation. The higher activation energy implies lower-barrier for phase transformation to occur. Equation (1) can be rewritten as,

$$
\log C=\log t-\left(\frac{Q}{2.3 R}\right)\left(\frac{1}{T}\right)+\log A
$$

where the $\log A$ is constant, it can be an arbitrary value in theory. To avoid negative value of $\log C, \log A$ is taken as 50 . If $\log C=\lambda$, then:

$$
\lambda=\log t-\left(\frac{Q}{2.3 R}\right)\left(\frac{1}{T}\right)+50
$$

Obviously, $\lambda$ is a physical parameter related to the amount of solid phase reaction, and the magnitude of this value directly determines the annealing process of steel. The hardness of steel after annealing $H$ is a function of $\lambda$. Using cubic polynomial expansion to fit $f(H)$, then:

$$
f(H)=C+C_{1} \log H+C_{2} \log ^{2} H+C_{3} \log ^{3} H=\log t-\left(\frac{Q}{19.12 T}\right)+50
$$

After re-arrangement, we have: 


$$
\log t=C+C_{1} \log H+C_{2} \log ^{2} H+C_{3} \log ^{3} H+\left(\frac{Q}{19.12}\right) \frac{1}{T}-50
$$

where, $C_{1} C_{1} 、 C_{2} 、 C_{3}$ and $Q$ are constant.

Assuming

$$
\begin{aligned}
& x_{0}=1, x_{1}=\log H, x_{2}=\log ^{2} M, x_{3}=\log ^{3} M, \\
& x_{4}=\frac{1}{T}, C_{0}=C-50, C_{4}=\frac{Q}{19.12}, y=\log t
\end{aligned}
$$

then the soft annealing function can be expressed as the following:

$$
\hat{y}=C_{0} x_{0}+C_{1} x_{1}+C_{2} x_{2}+C_{3} x_{3}+C_{4} x_{4}
$$

To get the unknown quantities, $n$ sets of annealing experiments at different temperatures and different times for each initial microstructure were needed. Substituting the $n$ experimental data $\left(T_{i}, t_{i}, H_{i}\right)$ into the equation (6), $n$ linear equations can be obtained as follows:

$$
\begin{gathered}
y_{1}=C_{0} x_{10}+C_{1} x_{11}+C_{2} x_{12}+C_{3} x_{13}+C_{4} x_{14} \\
y_{2}=C_{0} x_{20}+C_{1} x_{21}+C_{2} x_{22}+C_{3} x_{23}+C_{4} x_{24} \\
\\
\quad \cdots \\
y_{n}=C_{0} x_{n 0}+C_{1} x_{n 1}+C_{2} x_{n 2}+C_{3} x_{n 3}+C_{4} x_{n 4}
\end{gathered}
$$

According to the solution of the five-element linear equations, it can be transformed into a coefficient over-determined matrix, and the values $C_{0}, C_{1}, C_{2}, C_{3}, C_{4}$ can be obtained.

\begin{tabular}{|c|c|c|c|c|c|c|c|c|}
\hline \multirow{2}{*}{$\begin{array}{l}\text { Processing (aus- } \\
\text { tenitizing tem- } \\
\text { perature/hold- } \\
\text { ing time/cooling } \\
\text { methods }{ }^{1} \text { ) }\end{array}$} & \multicolumn{5}{|c|}{$\begin{array}{c}\text { Soft Annealing equation } \\
\left(\log t=C_{0}+C_{1} \log H+C_{2} \log ^{2} H+\log ^{3} H+\frac{C_{4}}{T}\right)\end{array}$} & \multirow{2}{*}{$R$} & \multirow{2}{*}{ Initial microstructure ${ }^{2}$} & \multirow{2}{*}{$Q(\mathrm{~J} / \mathrm{mol})$} \\
\hline & $C_{0}$ & $C_{1}$ & $C_{2}$ & $C_{3}$ & $C_{4}$ & & & \\
\hline hot-rolled & 2381.6 & -2928.1 & 1199.7 & -163.9609 & 3743.2 & 0.92 & $\mathrm{~B}_{\mathrm{F}}, \mathrm{M} / \mathrm{A}, \mathrm{Cem}(4.00 \%)$ & 71944 \\
\hline $680^{\circ} \mathrm{C} / 1 \mathrm{~h} / \mathrm{AC}$ & 4471.2 & -5526.5 & 2276.9 & -312.8366 & 3471.1 & 0.90 & $\mathrm{~B} F, \mathrm{M} / \mathrm{A}, \mathrm{Cem}(11.33 \%)$ & 66715 \\
\hline $680^{\circ} \mathrm{C} / 1 \mathrm{~h} / \mathrm{OQ}$ & 4405.3 & -5409.8 & 2214.7 & -302.3671 & 3121.9 & 0.90 & $\mathrm{~B}_{\mathrm{F}}, \mathrm{M} / \mathrm{A}, \mathrm{Cem}(8.51 \%)$ & 60003 \\
\hline $680^{\circ} \mathrm{C} / 1 \mathrm{~h} / \mathrm{WQ}$ & 3873.1 & -4761.2 & 1951.3 & -266.7286 & 3201.3 & 0.83 & $\mathrm{~B} F, \mathrm{M} / \mathrm{A}, \mathrm{Cem}(11.73 \%)$ & 61529 \\
\hline $850^{\circ} \mathrm{C} / 1 \mathrm{~h} / \mathrm{AC}$ & 2570.8 & -3198.7 & 1326.7 & -183.5172 & 2766.5 & 0.98 & $\mathrm{~B}$ F, M/A, Cem(4.88\%) & 53172 \\
\hline $850^{\circ} \mathrm{C} / 1 \mathrm{~h} / \mathrm{OQ}$ & 3363.7 & -4193.5 & 1742.1 & -241.3281 & 3741.6 & 0.98 & $\mathrm{~B} F, \mathrm{M} / \mathrm{A}, \mathrm{M}$ & 71914 \\
\hline $850^{\circ} \mathrm{C} / 1 \mathrm{~h} / \mathrm{WQ}$ & 3390.7 & -4197.9 & 1732.2 & -238.2545 & 1996.4 & 0.93 & M & 38371 \\
\hline $1000^{\circ} \mathrm{C} / 1 \mathrm{~h} / \mathrm{AC}$ & 2453.9 & -3034.3 & 1250.5 & -171.8882 & 3084.9 & 0.93 & $\mathrm{~B} F, \mathrm{M} / \mathrm{A}, \mathrm{Cem}(4.99 \%)$ & 59292 \\
\hline $1000^{\circ} \mathrm{C} / 1 \mathrm{~h} / \mathrm{OQ}$ & 3873.1 & -3870.7 & 1584.5 & -216.2508 & 2089.3 & 0.92 & M & 40156 \\
\hline $1000^{\circ} \mathrm{C} / 1 \mathrm{~h} / \mathrm{WQ}$ & 3054.1 & -3754.3 & 1538.2 & -210.0959 & 2054.5 & 0.96 & M & 39487 \\
\hline
\end{tabular}
To verify the validity of soft annealing equation, a comparison between the calculated hardness and measured value after annealing was performed for hot-rolled samples. It was shown that the calculated value is generally in good agreement with the experimental value, and the correlation coefficient is 0.92 . The coefficients of soft annealing equations for all initial microstructures were listed in Table 2.

Table 2. Soft Annealing equation of different microstructure and the corresponding correlation coefficients. 
${ }^{2}$ B F represents bainite ferrite, $\mathrm{M} / \mathrm{A}$ represents martensite/retained austenite islands and Cem represents carbides in initial microstructure.

Once the soft annealing equation of a certain initial microstructure was obtained through limited number of experiments, it can be utilized to predict the required holding time at a specific annealing temperature or the required annealing temperature at a specific holding time for a desired hardness. Hence, the window of annealing process can be determined, and experimental verification can be preferentially performed around the predicted value, thereby reducing the number of experiments.

\subsection{Effect of initial microstructure on activation energy}

In soft annealing equation, $C_{4}=Q / 19.22$, where $Q$ is the diffusion activation energy. The higher the value of $Q$, the greater the energy required for atomic diffusion, and the more difficult to soften the steel during annealing.

According to Table 2, the martensitic structure typically has an activation energy less than $50 \mathrm{~kJ} / \mathrm{mol}$. Whereas, initial microstructures that are bainitic correspond to activation energies greater than $50 \mathrm{~kJ} / \mathrm{mol}$.

By comparing the bainitic microstructure features, it was found that the content of $\mathrm{M} / \mathrm{A}$ islands and carbides influence the activation energy of bainite. For example, the initial structure of $850^{\circ} \mathrm{C} / 1 \mathrm{~h} / \mathrm{AC}$ and $1000^{\circ} \mathrm{C} / 1 \mathrm{~h} / \mathrm{AC}$ has lower carbide content, and the corresponding activation energy is higher. In contrast, if the initial structure contains preexisting carbides, they will act as of the core fore spheroidization in subsequent annealing process. In addition, the content of martensite and retained austenite in the M/A island also affect the soft annealing of bainite. When the content of retained austenite in the M/A island is large, the barrier of bainite decomposition is greater. It was verified by that the activation energy of $1000^{\circ} \mathrm{C} / 1 \mathrm{~h} / \mathrm{AC}$ is much lower than that of other bainitic initial microstructure.

\section{Conclusions}

In summary, based on the thermodynamic calculation of phase stability, the austenitizing route before annealing was designed and the different initial microstructures were prepared. The subsequent annealing was carried out to study the effect of initial microstructures on annealing hardness. The $\lambda$ parameter method was used to obtain the soft annealing equations for different initial microstructures, which quantitatively describe the relationship between annealing hardness, holding time, annealing temperature, and diffusion activation energy. In comparison, the diffusion activation energy of bainite is greater than that of martensite. And the content of M/A islands and carbides in bainite can also influence the activation energy of the bainitic structures.

\section{References}

1. Zou, D., Rock Drilling. In Theory and Technology of Rock Excavation for Civil Engineering, Springer Singapore: Singapore, 2017; pp 49-103.

2. He, Y.; Zhong, X.; Hu, J.; Hou, D.; Zhang, Z.; Zeng, D.; Shi, T., Monitoring corrosion fatigue crack formation on drill steel using electrochemical impedance spectroscopy: Experiment and modeling. Corrosion Science 2020, 175.

3. Yu, W.; Xie, B.-s.; Wang, B.; Cai, Q.-W.; Xu, S.-x., Effect of Rolling Process on Microstructure and Properties of 95CrMo Drill Steel. Journal of Iron and Steel Research International 2016, 23, (9), 910-916.

4. Zhao, M.-C.; Unenbayar, T.; Zhao, Y.-C.; Liu, C.; Tian, Y.; Yin, D.; Atrens, A., Influence of Tempering Temperature on the Microstructure and Mechanical Properties of a Cr-Ni-Mo-Alloyed Steel for Rock Drill Applications. steel research international 2019, 90, (12).

5. Abbasi, E.; Rainforth, W. M., Microstructural evolution during bainite transformation in a vanadium microalloyed TRIP-assisted steel. Materials Science and Engineering: A 2016, 651, 822-830.

6. Zaefferer, S.; Ohlert, J.; Bleck, W., A study of microstructure, transformation mechanisms and correlation between microstructure and mechanical properties of a low alloyed TRIP steel. Acta Materialia 2004, 52, (9), 2765-2778.

7. Yan, T.; Yu, E.; Zhao, Y., Constitutive modeling for flow stress of 55SiMnMo bainite steel at hot working conditions. Materials \& Design 2013, 50, 574-580.

8. Bhadeshia, H. K. D. H., Bainite in steels: theory and practice. CRC Press: 2019. 
9. Wang, B.; Song, X.; Peng, H., Design of a spheroidization processing for ultrahigh carbon steels containing Al. Materials $\mathcal{E}$ Design 2007, 28, (2), 562-568.

10. Bhadeshia, H. K. D. H., Steels for bearings. Progress in Materials Science 2012, 57, (2), 268-435.

11. Han, D.-X.; Du, L.-X.; Zhang, B.; Misra, R. D. K., Effect of deformation on deformation-induced carbides and spheroidization in bearing steel. Journal of Materials Science 2018, 54, (3), 2612-2627.

12. Yi, H. L.; Hou, Z. Y.; Xu, Y. B.; Wu, D.; Wang, G. D., Acceleration of spheroidization in eutectoid steels by the addition of aluminum. Scripta Materialia 2012, 67, (7-8), 645-648.

13. Saha, A.; Mondal, D. K.; Maity, J., Effect of cyclic heat treatment on microstructure and mechanical properties of $0.6 \mathrm{wt} \%$ carbon steel. Materials Science and Engineering: A 2010, 527, (16-17), 4001-4007.

14. Yao, S.-J.; Du, L.-X.; Wang, G.-D., Microstructure of Nb-Bearing Pipeline Steel with Improved Property Applying Ultrafast Cooling Process. steel research international 2014, 85, (1), 60-66.

15. Zhang, S. L.; Sun, X. J.; Dong, H., Effect of deformation on the evolution of spheroidization for the ultra high carbon steel. Materials Science and Engineering: A 2006, 432, (1-2), 324-332.

16. Su, S.-r.; Song, R.-b.; Chen, C.; Wang, J.-y.; Zhang, Y.-c., The novel process of spheroidizing-critical annealing used to optimize the properties of carburized steel and its effect on hardening mechanism of quenching and tempering. Materials Science and Engineering: A 2019, 765. 